\title{
PPAR $\beta$ activation inhibits melanoma cell proliferation involving repression of the Wilms' tumour suppressor WT1
}

\author{
Jean-François Michiels • Christophe Perrin • \\ Nathalie Leccia • Daniela Massi • Paul Grimaldi • \\ Nicole Wagner
}

Received: 19 August 2009 /Revised: 30 November 2009/Accepted: 15 December 2009/Published online: 12 January 2010

(C) The Author(s) 2010. This article is published with open access at Springerlink.com

\begin{abstract}
Peroxisome proliferator-activated receptors (PPARs) are ligand-activated transcription factors that strongly influence molecular signalling in normal and cancer cells. Although increasing evidence suggests a role of PPARs in skin carcinogenesis, only expression of PPAR $\gamma$ has been investigated in human melanoma tissues. Activation of PPAR $\alpha$ has been shown to inhibit the metastatic potential, whereas stimulation of PPAR $\gamma$ decreased melanoma cell proliferation. We show here that the third member of the PPAR family, PPAR $\beta / \delta$ is expressed in human melanoma samples. Specific pharmacological activation of PPAR $\beta$ using GW0742 or GW501516 in low concentrations inhibits proliferation of human and murine melanoma cells. Inhibition of proliferation is accompanied
\end{abstract}

Jean-François Michiels and Christophe Perrin contributed equally.

J.-F. Michiels $\cdot$ C. Perrin · N. Leccia $\cdot$ P. Grimaldi $\cdot$ N. Wagner Université de Nice-Sophia Antipolis,

06108 Nice, France

J.-F. Michiels $\cdot$ C. Perrin $\cdot$ N. Leccia

Department of Pathology,

CHU Nice 06107 Nice, France

\section{Massi}

Department of Human Pathology and Oncology,

University of Florence,

50134 Florence, Italy

P. Grimaldi • N. Wagner

INSERM U907,

06107 Nice, France

N. Wagner $(\bowtie)$

INSERM U907, Faculté de Médecine,

Université de Nice-Sophia Antipolis,

28, Avenue Valombrose,

06107 Nice, France

e-mail: nwagner@unice.fr by decreased expression of the Wilms' tumour suppressor 1 (WT1), which is implicated in melanoma proliferation. We demonstrate that PPAR $\beta$ directly represses WT1 as (1) PPAR $\beta$ activation represses WT1 promoter activity; (2) in chromatin immunoprecipitation and electrophoretic mobility shift assays, we identified a binding element for PPAR $\beta$ in the WT1 promoter; (3) deletion of this binding element abolishes repression by PPAR $\beta$ and (4) the WT1 downstream molecules nestin and zyxin are down-regulated upon PPAR $\beta$ activation. Our findings elucidate a novel mechanism of signalling by ligands of PPAR $\beta$, which leads to suppression of melanoma cell growth through direct repression of WT1.

Keywords PPAR $\beta \cdot$ WT1 1 Melanoma Proliferation .

Transcriptional regulation - Tumour .

Immunohistochemistry $\cdot$ Cancer cells $\cdot$ Skin $\cdot$ Cell line

\section{Introduction}

The incidence of malignant melanoma has been increasing steadily worldwide as a consequence of excessive exposure to sunlight $[4,14]$. A sensitive skin phenotype with fair skin, tendency to burn, inability to tan, the presence of dysplastic nevi, family history of melanoma and immunosuppression are established risk factors [9, 35]. Despite advancements in early diagnosis and treatment of melanoma, morbidity and mortality do not decrease most likely because of poor understanding of the molecular mechanisms involved in skin repair, skin carcinogenesis and melanoma growth.

Increasing evidence suggests a role of peroxisome proliferator-activated receptors (PPARs) in skin formation, repair and skin carcinogenesis (reviewed in [28]). PPARs 
belong to the nuclear receptor superfamily of ligandactivated transcription factors [36]. They exist in three different isoforms termed PPAR $\alpha, \operatorname{PPAR} \beta / \delta$ and PPAR $\gamma$. All PPARs form heterodimers with retinoic $\mathrm{X}$ receptors, and, upon ligand binding, use the basal transcriptional machinery to regulate gene expression [24]. PPARs are expressed during normal skin development in the epidermis, hair follicles and sebaceous glands. In contrast to humans, where PPARs are also expressed in the adult epidermis, in rodents, PPARs are down-regulated in the epidermis after birth (reviewed in [28]). In skin repair, PPAR $\alpha$ and $\operatorname{PPAR} \beta$, but not PPAR $\gamma$, expression is up-regulated in keratinocytes [27]. In this case, PPAR $\beta$ is transcriptionally activated via the $\mathrm{TNF}-\alpha$ pathway leading to survival, migration and differentiation of keratinocytes [38].

Several studies suggested that PPAR activation could interfere with skin carcinogenesis. Mice fed with a PPAR $\alpha$ activator were more resistant to chemically induced carcinogenesis [40]. In line with this, PPAR $\beta-$ and $\operatorname{PPAR} \gamma$-deficient mice were more susceptible against chronic application of chemical carcinogens [22, 31]. Less is known about the role of PPARs, especially PPAR $\beta$ in melanocytes and melanoma. mRNA expression of all PPARs has been described in human melanocytes, and $\operatorname{PPAR} \alpha$ and $\gamma$ activators were shown to inhibit cell proliferation and to stimulate melanin synthesis [21]. Expression of PPAR $\alpha$ has been detected in melanoma cells $[11,16,17]$ as well as in human melanoma samples (Wagner et al., unpublished observation). Pharmacological PPAR $\alpha$ activation has been shown to inhibit the metastatic potential of melanoma cells, whereas no effect on proliferation could be observed [11, 16, 17]. In human melanoma samples, PPAR $\gamma$ expression was demonstrated, and PPAR $\gamma$ agonists were shown to inhibit the proliferation of human melanoma cell lines [29]. In addition, PPAR $\beta$ mRNA expression had been reported in one melanoma cell line [15]. However, PPAR $\beta$ expression in melanoma in vivo and its possible functional relevance have not been investigated yet.

Therefore, our study served the purposes to examine (1) PPAR $\beta$ expression in melanoma in vivo, (2) to clarify the functional consequences of PPAR $\beta$ activation in melanoma cells and (3) to elucidate possible molecular downstream pathways of PPAR $\beta$ activation in melanoma cells.

Here we show that PPAR $\beta$ is expressed in human melanoma samples. Pharmacological PPAR $\beta$ activation in human and murine melanoma cells at low doses inhibits cell proliferation without inducing apoptosis. This growth inhibition of melanoma cells is accompanied by a decrease in the expression of the Wilms' tumour suppressor (WT1). Finally, we demonstrate that PPAR $\beta$ directly binds to the WT1 promoter and represses its activity, therefore inhibiting the growth promoting effects of WT1 on melanoma cells.

\section{Materials and methods}

\section{Cell culture}

Human and mouse melanoma cell lines (A375, accession number CRL-1676, B16F0, accession number CRL-6322) were grown in Dulbecco's modified eagle's medium supplemented with $10 \%$ fetal calf serum, $100 \mathrm{IU} / \mathrm{ml}$ penicillin and $100 \mu \mathrm{g} / \mathrm{ml}$ streptomycin. Media and reagents were obtained from Invitrogen (Cergy Pontoise, France). A375 or B16F0 cells were maintained for $24 \mathrm{~h}$ in medium in the presence of GW0742 (Glaxo Smith Kline, Research Triangle Park, USA) or GW501516 (Alexis Biochemicals, Coger S.A., Paris, France) dissolved in dimethyl sulfoxide (DMSO) at concentrations of 100 or $500 \mathrm{nmol} / \mathrm{l}$. Controls were treated with vehicle (DMSO) only.

\section{Detection of cell proliferation}

A375 and B16F0 cells were split into 96-well dishes, treated with GW0742, GW501516 or vehicle (DMSO). Additionally, B16F0 cells were treated with GW0742 in the presence or absence of a dominant negative PPAR $\beta$ isoform (3) and A375 cells after transfection with WT1 expression constructs or PPAR $\beta$ siRNA constructs. After $24 \mathrm{~h}$, bromodeoxyuridine was added and the cells incubated for $3 \mathrm{~h}$. Afterwards, cells were fixed and BrdU incorporation detected using a mouse monoclonal anti-BrdU antibody followed by incubation with a goat anti-mouse IgG peroxidase-coupled secondary antibody with TMB as peroxidase substrate and spectrophotometrical reading of the plates at $450 \mathrm{~nm}$ according to the manufacturer's instructions (Millipore, Molsheim, France). Alternatively, $24 \mathrm{~h}$ after GW treatment, cells were methanol fixed and immunohistochemical detection of proliferating cell nuclear antigen (PCNA) was performed as described [44] with counterstaining of nuclei using 4',6-diamidino-2-phenylindole (DAPI; Vector Laboratories, Burlingame, CA, USA).

Apoptosis assay

Apoptotic cells were detected by TdT-dUTP terminal nickend labelling (TUNEL) staining $24 \mathrm{~h}$ after GW0742 treatment using the in situ cell death detection kit (Roche Molecular Biochemicals, Meylan, France) as described [44].

Sodium dodecyl sulphate-polyacrylamide gel electrophoresis and Western blot

Total cell lysates were prepared, electrophoresed and blotted as described [47]. The following antibodies were used for immunodetection: polyclonal anti-WT1 antibody from rabbit (C-19, sc-846, Santa Cruz Biotechnology, 
Heidelberg, Germany; 1:500 dilution in phosphate-buffered saline (PBS), 2.5\% Blotto, $0.05 \%$ Tween-20), polyclonal anti-PPAR $\beta$ from rabbit (H-74, sc-7197, Santa Cruz Biotechnology, 1:500), monoclonal anti-nestin from mouse (MAB5326 and MAB353, Millipore, 1:500), polyclonal anti-zyxin antibody from rabbit (kind gift of M. Beckerle, $1: 1,000$ ), polyclonal anti-GAPDH from goat (L-20, sc-31915, Santa Cruz Biotechnology, 1:500) and polyclonal anti-actin from goat (C-11, sc-1615, Santa Cruz Biotechnology, 1:500) and peroxidase-coupled goat anti-rabbit secondary antibody (1:2,000, Vector Laboratories), peroxidase-coupled horse anti-goat secondary antibody (1:2,000, Vector Laboratories) and peroxidase-coupled horse anti-mouse secondary antibody (1:2,000, Vector Laboratories).

\section{Quantitative RT-PCR}

Reverse transcriptase polymerase chain reaction (RT-PCR) was performed with $2 \mu \mathrm{g}$ of total RNA as described [47]. The following primers were used for PCR amplification: human WT1 (NCBI accession no. NM005238), 5'-GGACA AGCCTGTCATTCCTG-3' (forward primer), 5'AAGAAACTGCCATAGCTGGATT-3' (reverse primer) and mouse wt1 (NCBI accession no. NM144783), 5'CAGATGAACCTAGGAGCTACCTTAAA-3' (forward primer), 5'-TGCCCTTCTGTCCATTTCA-3' (reverse primer). Expression was normalised to the individual levels of the housekeeping gene GAPDH using the following primers: human GAPDH (NCBI accession no. NM002046), 5'-AGCTGTCCCACTTACAGATGC-3' (forward primer), 5'-CCTTGAAGTCACACTGGTATGG-3' (reverse primer) and mouse GAPDH (NCBI accession no. NM008084), 5'-ATTCAACGGCACAGTCAAGG-3' (forward primer), 5'-TGGATGCAGGGATGATGTTC-3' (reverse primer).

Transient transfection experiments

To investigate the effect of PPAR $\beta$ expression on WT1 promoter activity, a 767-bp fragment of the WT1 promoter in the pGl2 basic luciferase expression vector was cotransfected with PPAR $\beta$ constructs. A375 and B16F0 cells were transfected at $60-80 \%$ confluency using Fugene 6 reagent (Roche Molecular Biochemicals) or Lipofectamine 2000 (Invitrogen), respectively. About $0.3 \mu \mathrm{g}$ of the reporter constructs together with $0.1 \mu \mathrm{g}$ of a cytomegalovirus (CMV)-driven $\beta$-galactosidase plasmid, and $1.6 \mu \mathrm{g}$ of the expression construct encoding PPAR $\beta$ were transiently cotransfected and assayed for luciferase- and $\beta$-galactosidase activity as described in detail elsewhere [47]. Alternatively, the WT1 promoter construct [42] was co-transfected only with the $\beta$-galactosidase reporter plasmid and the cells cultured for $48 \mathrm{~h}$ in the presence of $200 \mathrm{nM} \mathrm{GW} 0742$ or vehicle. The putative PPAR responsive element was deleted from the WT1 promoter construct using the Quik Change II site directed mutagenesis kit (Stratagene, Agilent Technologies, Massy, France) with the following oligonucleotides 5'-CCCCGCAGCTAGCCTGGACATGGGAG-3' (forward, reverse primer in the corresponding antisense orientation). This deletion construct was again co-transfected with the PPAR $\beta$ expression construct. To obtain transient overexpression of WT1, A375 cells were transfected with plasmids encoding either the WT1(-KTS) or the WT1 (+KTS) splice variant or a combination of both isoforms (50:50\% ratio). The empty expression vector (pCB6+) served as negative control. To down-regulate PPAR $\beta$ expression, siRNA constructs directed against human PPAR $\beta$ (sc-36305-SH, Santa Cruz Biotechnology) were transfected. Subsequently, GW0742 or vehicle (DMSO) was added to the cultures for a period of $24 \mathrm{~h}$ before Western blot or BrdU incorporation-based proliferation analysis.

\section{Chromatin immunoprecipitation assay}

Chromatin immunoprecipitation (ChIP) assay was performed on B16F0 cells using manufacturer's instructions (Millipore). Antibodies (3 $\mu \mathrm{g}$ each) against acetylated histone 3 (rabbit polyclonal antibody, 06-599, Millipore) and PPAR $\beta$ (rabbit polyclonal antibody H-74, sc-7197, Santa Cruz Biotechnology) were used. Normal rabbit serum served as a negative control and a 1:5 and a 1:10 dilution of the input sample as positive control. The histone H3 antibody was used to check for preservation of nucleosomes at the genomic locus. Following immunoprecipitation, the purified DNA was eluted in $30 \mu 1$ UltraPure DNase, RNase-free water (Sigma, Saint-Quentin Fallavier, France). For amplification of purified DNA fragments by PCR, $1 \mu 1$ of the diluted input DNA or the immunoprecipitated DNA's were mixed with primers, DNase-free water and Red Taq Ready mix (Sigma). The following primers were used: WT1 promoter, 5'-CGCAGCTAGCCTCTAG AATT-3' (forward), 5'-GCCGTCTAGGTAAGTAATGA-3' (reverse); 3'UTR, 5'-TTCAAGGTGTCTAGAAAGTC-3' (forward), 5'-TTACATTAGCAGGCACATAC-3' (reverse). PCR products were electrophoresed on a $2 \%$ agarose gel yielding DNA fragments of 215 and 196 bp, respectively.

Electrophoretic mobility shift assays

The putative PPAR responsive element from the WT1 promoter contained the following sequence: $5^{\prime}$-TAGCCTC TAGAATTCTGGACATGGGA-3'. The PPAR responsive element from the acyl-CoA oxidase gene (5'-CCCGAACG TGACCTTTGTCCTGGTCC-3') served as positive control. 
Table 1 Summary of tumour lesions used for the investigation of PPAR $\beta$ expression

\begin{tabular}{|c|c|c|c|c|c|c|c|}
\hline No. & Sex & Age & Location & Histological type & Ulceration & Clark's level & Breslow thickness $(\mathrm{mm})$ \\
\hline 1 & $\mathrm{~m}$ & 82 & Shoulder & $\mathrm{NM}$ & Present & IV & 2 \\
\hline 2 & $\mathrm{~m}$ & 61 & Back & NM & Present & IV & 7.5 \\
\hline 3 & $\mathrm{f}$ & 65 & Arm & $\mathrm{NM}$ & Absent & IV & 5 \\
\hline 4 & $\mathrm{f}$ & 77 & Arm & $\mathrm{NM}$ & Absent & III & 1.2 \\
\hline 5 & $\mathrm{f}$ & 70 & Back & $\mathrm{NM}$ & Absent & IV & 3.6 \\
\hline 6 & $\mathrm{~m}$ & 77 & Thigh & SSM & Present & IV & 1.3 \\
\hline 7 & $\mathrm{~m}$ & 87 & Shoulder & SSM & Present & IV & 2.7 \\
\hline 8 & $\mathrm{f}$ & 56 & Trunk & SSM & Present & IV & 5.5 \\
\hline 9 & $\mathrm{~m}$ & 52 & Back & SSM & Absent & IV & 2.1 \\
\hline 10 & $\mathrm{~m}$ & 70 & Abdomen & SSM & Present & IV & 3 \\
\hline 11 & $\mathrm{~m}$ & 69 & Back & SSM & Absent & IV & 1.7 \\
\hline 12 & $\mathrm{f}$ & 47 & Leg & SSM & Absent & IV & 1.45 \\
\hline 13 & $\mathrm{f}$ & 74 & Leg & Metastasis & Absent & NA & NA \\
\hline
\end{tabular}

To predict the likelihood of metastatic spread at the time of surgery, Breslow's tumour thickness, ulceration and Clark's level are the currently most accepted prognostic factors [2]

$N M$ nodular melanoma, SSM superficial spreading melanoma, $N A$ not applicable

Annealed oligonucleotides were ${ }^{32} \mathrm{P}$-end labelled in a $\mathrm{T} 4$ polynucleotide kinase reaction (New England Biolabs, Ozyme, Saint Quentin Yvelines, France). PPAR $\beta$ and $\mathrm{RxR} \alpha$ proteins were generated from full-length cDNAs in pSG5 vector (Stratagene) using the coupled TNT in-vitrotranscription-translation system (Promega, Charbonnières-les Bains, France). For supershift assays, the same antibodies as for the ChIP experiments were used. DNA binding reactions were performed on ice for $30 \mathrm{~min}$ with approximately $20 \mathrm{ng}$ of proteins in $15 \mu \mathrm{l}$ of a $1 \times$ reaction buffer containing $10 \mathrm{mM}$ Tris-HCl, pH 7.5, $50 \mathrm{mM} \mathrm{KCl,} 50 \mathrm{mM} \mathrm{NaCl}, 1 \mathrm{mM} \mathrm{MgCl}{ }_{2}$, $1 \mathrm{mM}$ EDTA, $5 \mathrm{mM}$ DTT, $5 \%$ glycerol and $0.025 \mathrm{mg} / \mathrm{ml}$ denatured herring sperm DNA. For supershift experiments, the reaction mixes were pre-incubated for $45 \mathrm{~min}$ with the PPAR $\beta$ antibodies mentioned above prior to addition of the labelled oligonucleotides.

\section{Tissue samples and immunohistology}

The study adheres to the principles of the Declaration of Helsinki and to title 45, US code of Federal Regulations, Part 46, Protection of human subjects. PPAR $\beta$ immunohistochemical expression was evaluated in normal skin samples $(n=5)$ and tissue specimens of cutaneous malignant melanomas (seven superficial spreading melanomas, five nodular melanomas and one subcutaneous melanoma metastasis), which were obtained from patients who had undergone surgery at the University of Nice or the University of Florence Medical School (Table 1). Tissues were fixed in $10 \%$ buffered formalin and paraffinembedded. Paraffin sections were dewaxed in xylene, hydrated in ethanol series and washed in phosphate- buffered saline. An antigen retrieval method using a pressure cooker was performed before immunohistochemical staining [33]. Antigen detection was performed using the EnVision + Dual Link System-HRP from Dako (Trappes, France) according to the manufacturer's instructions using Vector VIP substrate (Vector VIP substrate kit, SK-4600, Vector Laboratories).

Polyclonal anti-PPAR $\beta$ from rabbit (H-74, sc-7197, Santa Cruz Biotechnology) or monoclonal anti-PPAR $\beta$ from mouse (MAB 3892, Millipore) were used in a dilution of 1:100 and 1:500 for the latter in PBS, 0.1\% bovine serum albumin and $0.1 \%$ Triton X-100. The primary antibody was replaced by normal serum in the negative controls. As an additional positive control to the PPAR $\beta$-positive keratinocytes in the skin samples, paraffin sections of human colon samples were equally processed, using DAB as a substrate. Sections were

Fig. 1 PPAR $\beta$ expression in normal skin, primary and metastatic melanoma. Representative examples of normal skin (a), nodular melanoma (b), a melanoma metastasis (c) and superficial spreading melanoma (d) stained for PPAR $\beta$ (rabbit polyclonal antibody and VIP as substrate, purple). Sections were counterstained with haematoxylin to visualise nuclei. Note the mostly nuclear expression of PPAR $\beta$ in keratinocytes, melanocytes and hair follicles and the heterogenous, both nuclear and cytoplasmatic expression in tumoural melanocytic lesions. Within the same melanoma metastasis, regions of moderate $(\mathbf{c}(b))$ and low (c (c)) PPAR $\beta$ expression coexist. In superficial spreading melanoma, PPAR $\beta$ expression dominated in the invasive front of the tumour (d). Arrows in (d (a)) indicate the position of the high-power magnifications of the invasive front $(\mathbf{d},(b))$ and adjacent tissue (epidermis) with melanocyte atypia (d $(c)$ ). No staining could be observed by replacing the first antibody with normal serum (e). Human colon sections served as additional positive $(\mathbf{f}(a))$ and negative $(\mathbf{f}(b))$ controls (DAB substrate, brown). Scale bars indicate $50 \mu \mathrm{m}$ 

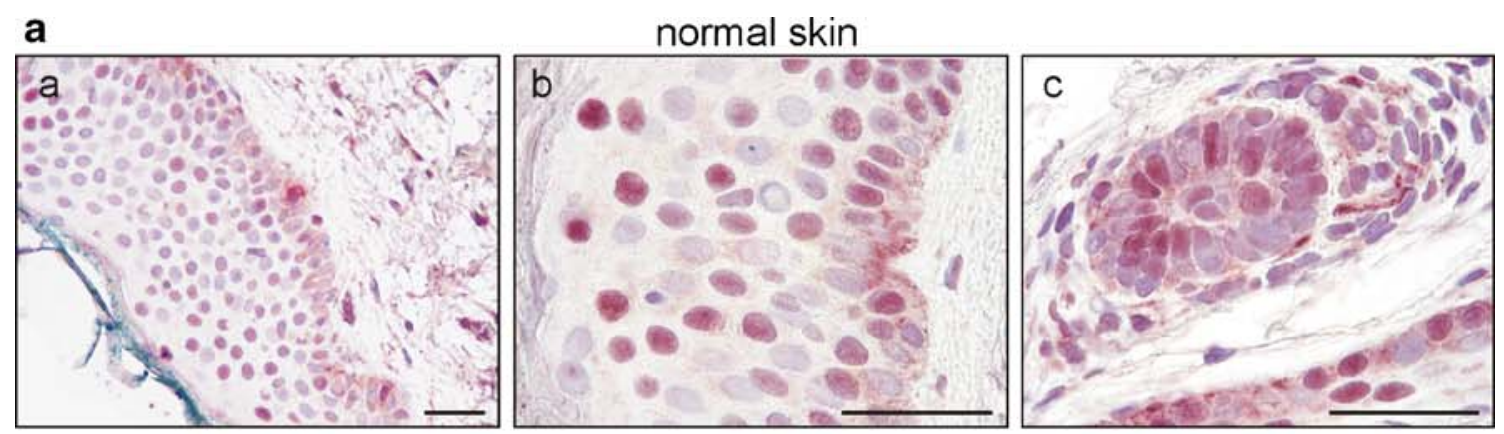

b
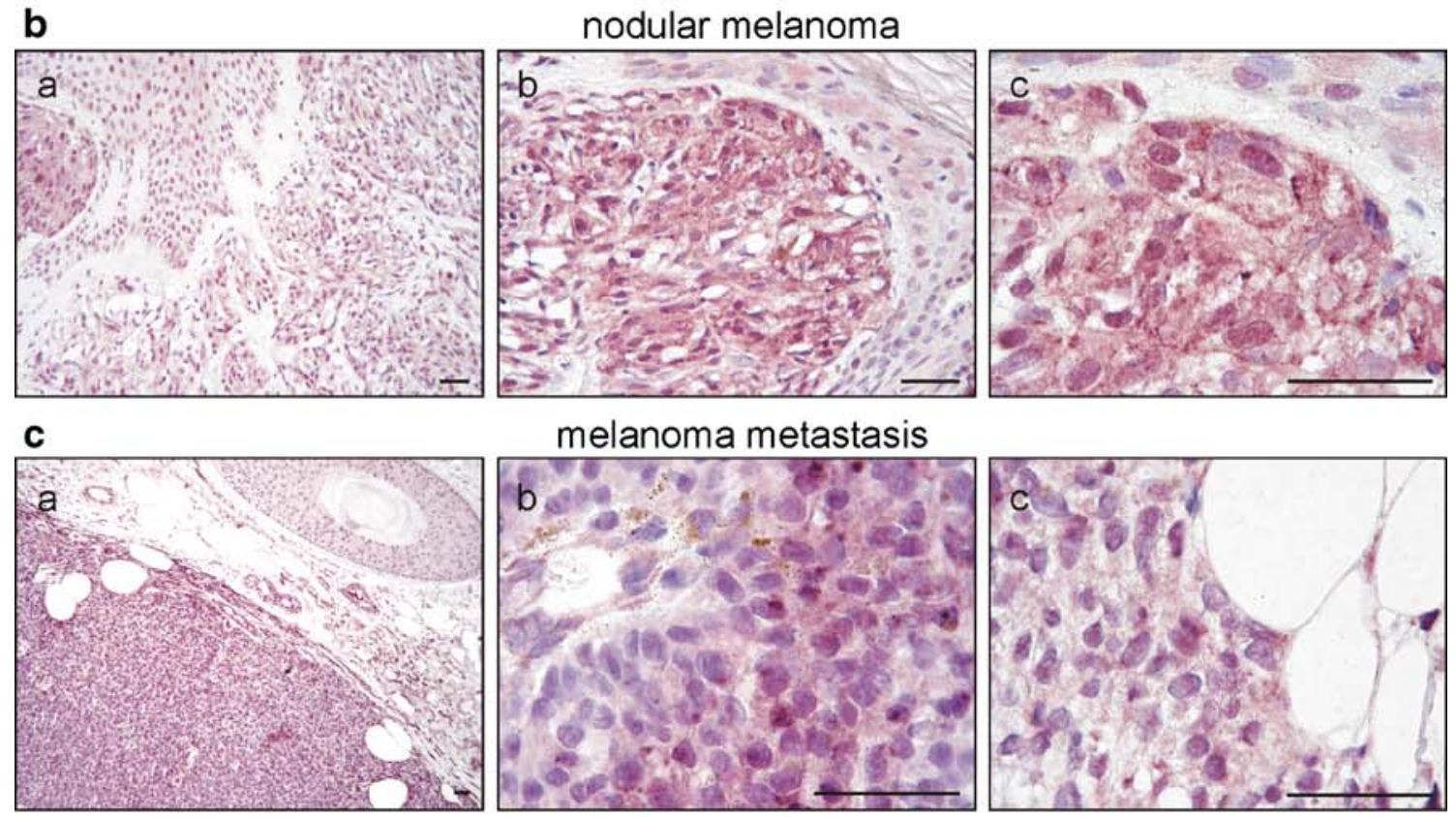

d

superficial spreading melanoma
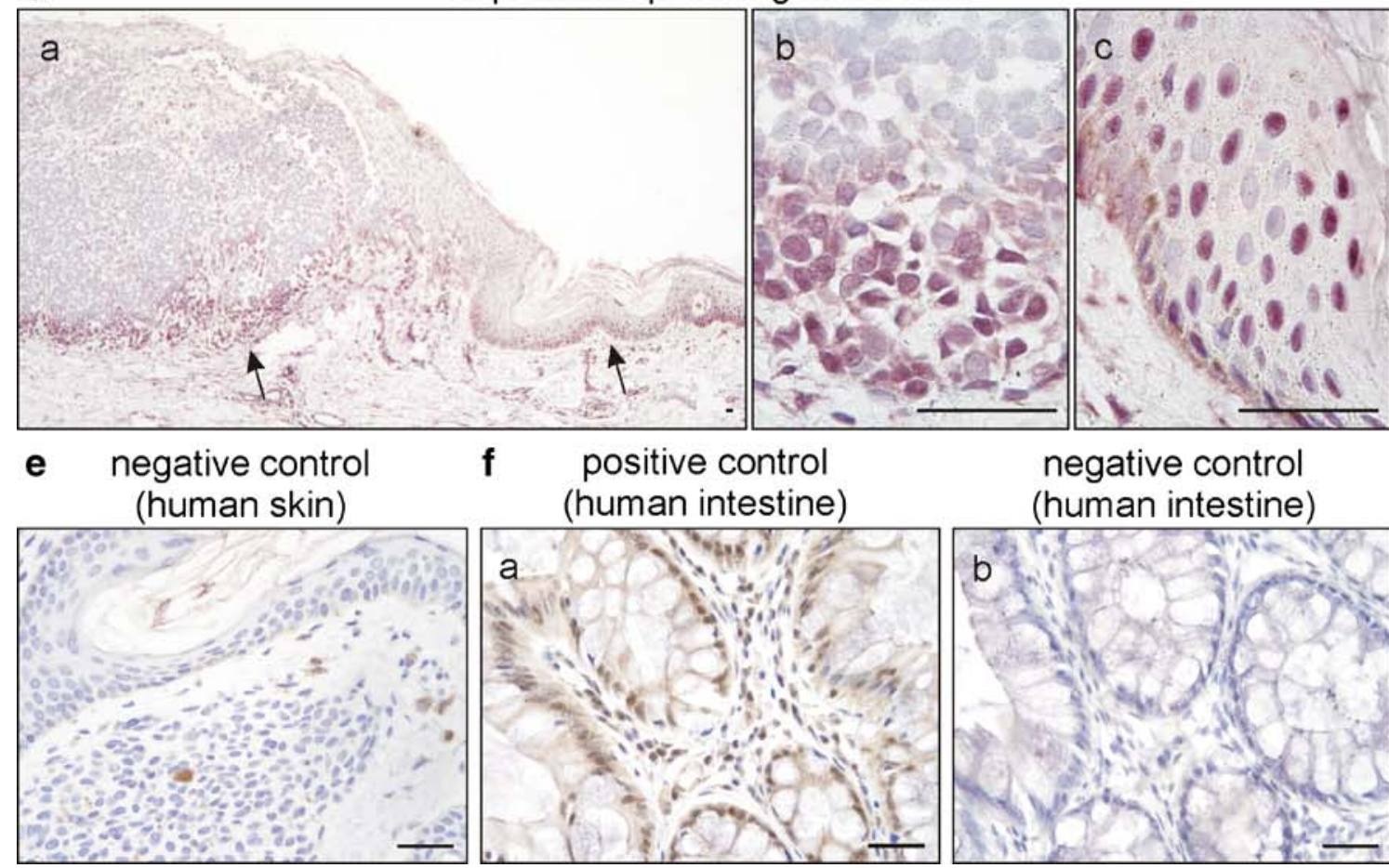

negative control

(human intestine)

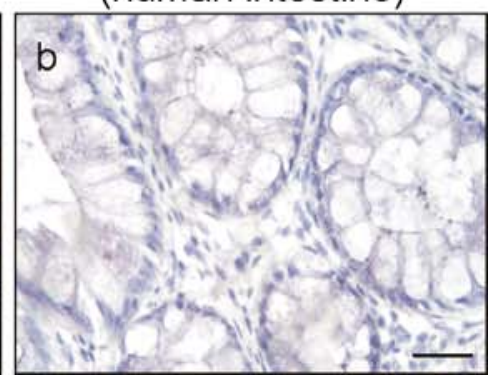


counterstained with hematoxylin (Sigma) and analysed by four independent investigators, three of them experienced dermatopathologists.

For immunofluorescence double-labelling, methanolfixed A375 cells or paraffin sections were incubated with the polyclonal PPAR $\beta$ antibody and a monoclonal antiWT1 antibody from mouse in a 1:100 dilution (clone 6FH2, MAB 4234, Millipore). Antigens were visualised using $\mathrm{Cy} 2$ and $\mathrm{Cy} 3$ coupled secondary antibodies in a 1:150 dilution (Jackson Immuno-Research, Suffolk, UK). Slides were viewed under an epifluorescence microscope (DMLB, Leica, Wetzlar, Germany) connected to a digital camera (Spot RT Slider, Diagnostic Instruments, Livingston, Scotland) with the Spot software (Universal Imaging, Downingtown, PA, USA).

\section{Statistics}

Data are expressed as means \pm SEM. ANOVA with the Bonferroni test as post hoc test was used vs. control. Differences between two groups were tested using the Mann-Whitney test for non-parametric samples. A $p$ value less than 0.05 was considered statistically significant.

\section{Results}

PPAR $\beta$ expression in normal skin and melanoma

Several reports focussed on PPAR $\beta$ expression and function in keratinocytes whereas to our knowledge, PPAR $\beta$ expression in melanocytes and melanoma in vivo has not been investigated yet. In normal human skin samples, epidermal keratinocytes, melanocytes, adipocytes, hair follicles, eccrine and sebaceous glands as well as vascular endothelial cells showed mostly nuclear immunoreactivity for PPAR $\beta$ (Fig. 1a). In all melanoma samples tested $(n=13)$, PPAR $\beta$ expression could be observed (Fig. 1b-d). This PPAR $\beta$ expression was heterogeneous, with both, a nuclear and granular cytoplasmic pattern. Interestingly, in nodular melanomas and in the melanoma metastasis, we observed an overall heterogeneous expression pattern within the tumour lesion, whereas, in all superficial spreading melanomas tested, less PPAR $\beta$ expression could be observed. In superficial spreading melanomas, however, PPAR $\beta$ expression was mostly confined to the deeper invasive front, which might suggest that PPAR $\beta$ could be connected to invasion or proliferation of melanoma cells. No staining could be observed when the first antibody was replaced with normal serum (Fig. 1e). In addition to the internal positive control of PPAR $\beta$ reactive keratinocytes, human colon sections were stained and depicted the described expression [20] of PPAR $\beta$ in epithelial, mesenchymal and crypt cells (Fig. 1f).

PPAR $\beta$ activation inhibits melanoma cell proliferation

To test the functional relevance of PPAR $\beta$ expression in melanoma cells, we made use of an in vitro approach and treated human (A375) and mouse (B16) cells with low and increasing doses of the specific PPAR $\beta$ agonists GW0742 or GW501516. Immunostainings for proliferating cell nuclear antigen and subsequent counting of positive cells revealed that already at a concentration of $100 \mathrm{nmol} / \mathrm{l} \mathrm{GW0742}$ as well as GW501516 proliferation of human and mouse melanoma cells was significantly reduced. This effect was even more pronounced at a concentration of $500 \mathrm{nmol} / 1 \mathrm{GW} 0742$ or GW501516 (Fig. 2a-d). Higher concentrations of $1 \mu \mathrm{mol} / 1$ or $2 \mu \mathrm{mol} / 1$ did not amplify the effect indicating receptor saturation at $500 \mathrm{nmol} / \mathrm{l}$ (data not shown). Inhibition of proliferation in response to pharmacological PPAR $\beta$ activation was confirmed in enzyme-linked immunosorbent assay based 5-bromodeoxyuridine (BrdU) incorporation experiments (Fig. 2e-g). Retroviral transduction of B16 mouse melanoma cells with a dominant negative PPAR $\beta$ isoform resulted in expression levels of approximately $175 \%$ of the dominant negative form compared to wild-type PPAR $\beta$ levels (Fig. 3a). The transduction completely abolished the anti-proliferative effect of GW0742 (Fig. 3b). The experiment could not be performed on human melanoma cells because the transduction method for the dominant negative PPAR $\beta$ isoform is rodent-specific [3]. Therefore, constructs containing siRNAs directed against human PPAR $\beta$ were transfected in A375 cells. This approach knocked down PPAR $\beta$ efficiently as confirmed by Western blot (Fig. 3c). The siRNA slightly increased proliferation under control conditions, which might result from blocking the effects of endogenous PPAR $\beta$ ligands. The siRNA against PPAR $\beta$ restored proliferation in the presence of different concentrations of GW0742 in A375 melanoma cells.

PPAR $\beta$ activation is not inducing apoptosis in melanoma cells

To clarify whether apoptosis might contribute to the reduced cell number in response to PPAR $\beta$ stimulation, we used TdT-dUTP terminal nick-end labelling with counterstaining of all cell nuclei with DAPI. This was followed by counting of TUNEL-positive cells and the total number of cells per optical field. Neither $100 \mathrm{nmol} / 1$ GW0742 or GW501516 nor $500 \mathrm{nmol} / 1$ of each of the specific PPAR $\beta$ agonists had a significant influence on apoptosis of melanoma cells (Fig. 4). 
A DMSO

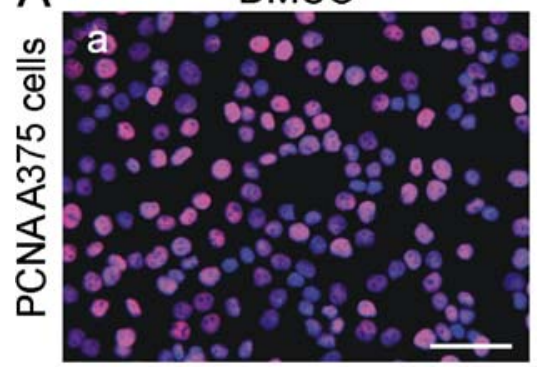

B
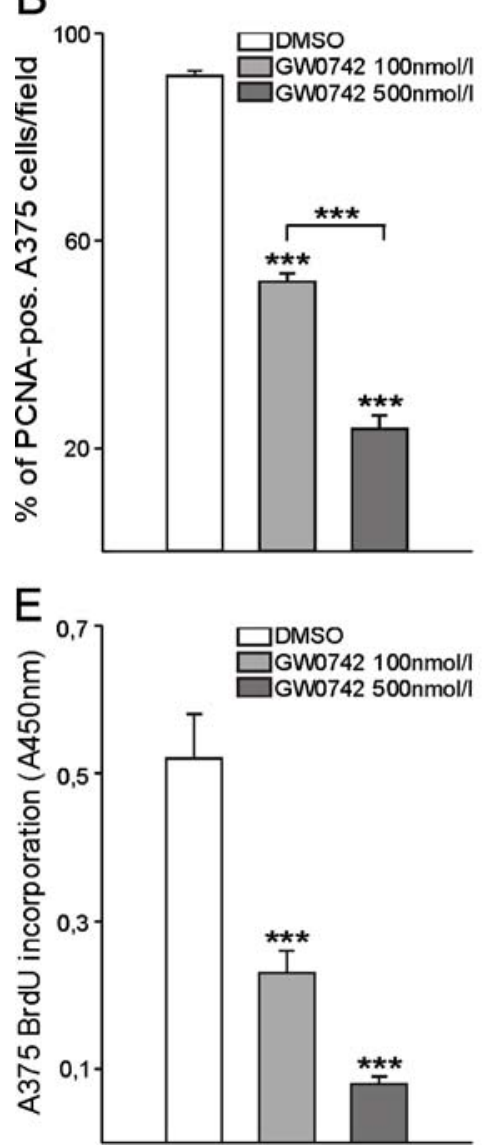

GW0742 100nmol/l

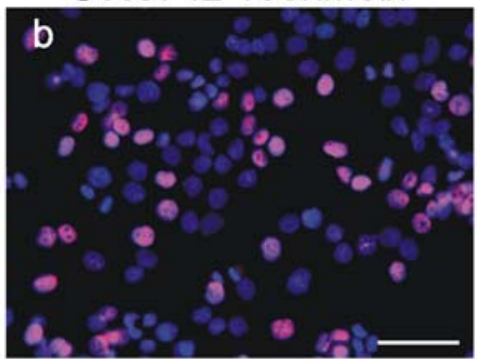

C

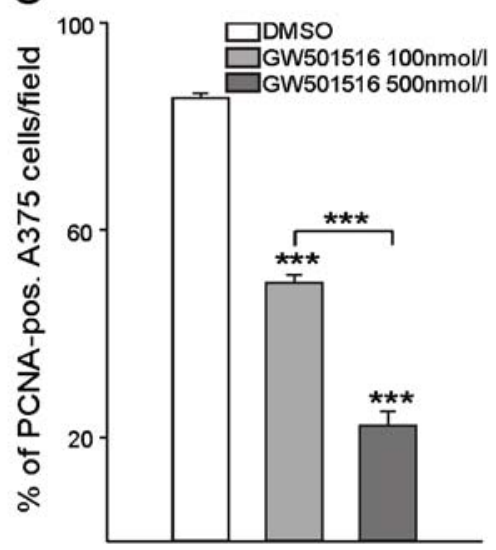

$\mathrm{F}$

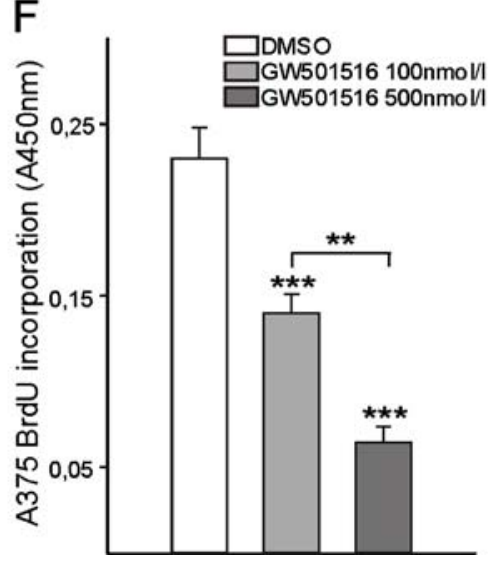

GW0742 500nmol/l

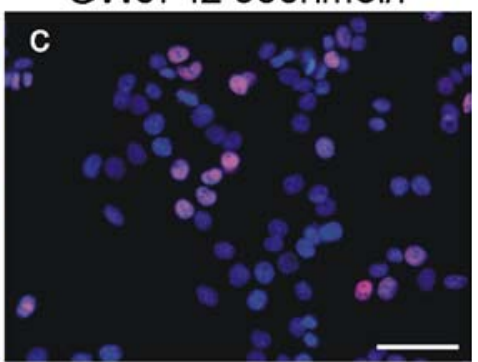

D
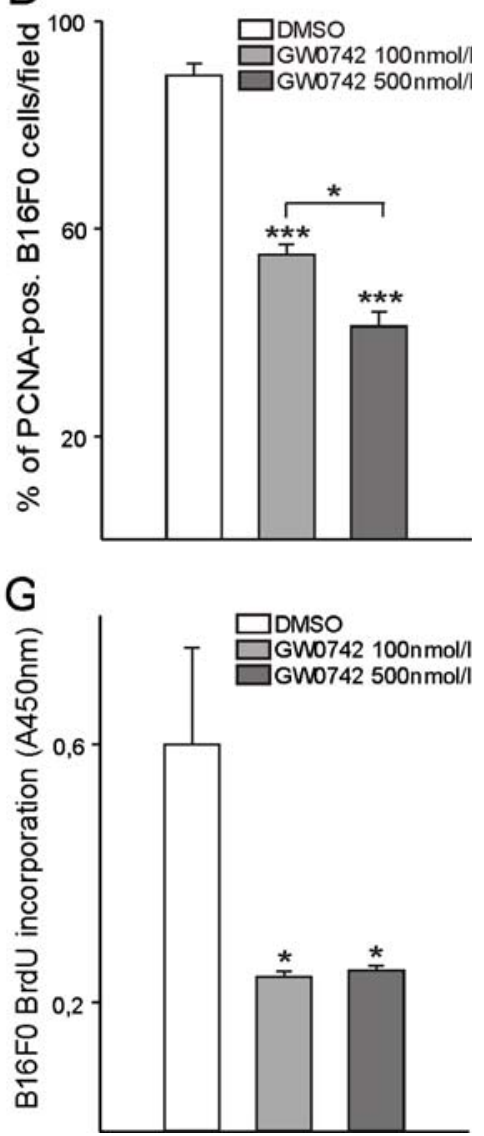

Fig. 2 Pharmacological PPAR $\beta$ activation in melanoma cell lines of human and murine origin. A375 (human) and B16F0 (mouse) melanoma cells were treated with different concentrations of two PPAR $\beta$ agonists, GW0742, or GW501516, for $24 \mathrm{~h}$. PPAR $\beta$ activation inhibits melanoma cell proliferation. PPAR $\beta$-agonist-treated cells were immunostained with an anti-proliferating cell nuclear antigen $(P C N A)$ antibody and counterstained with DAPI $(\mathbf{a}(a-c))$. Cells in seven random optical fields were counted and the percentage of PCNApositive cells determined (b-d; for each cell line and each agonist, $n=3, P<0.001)$. Alternatively $(\mathbf{e}-\mathbf{g})$, cells were incubated with 5-bromodeoxyuridine $(\mathrm{Brd} U)$ followed by immunological detection of the incorporated $\mathrm{BrdU}$ (for each cell line and each agonist, $n=4, P<$ 0.001 for A375 cells and, $P<0.05$ for $\mathrm{B} 16 \mathrm{~F} 0$ cells)

PPAR $\beta$ activation. In quantitative RT-PCR analyses, we determined that WT1 RNA levels were reduced upon PPAR $\beta$ stimulation in human (Fig. 5a) as well as in mouse (Fig. 5b) melanoma cells. Using Western blot analyses, we found that although PPAR $\beta$ expression seems to be lower in the mouse cells compared to the human cell lines, in both cases stimulation of the receptor with different concentrations of GW0742 did not affect PPAR $\beta$ protein expresinvolved in the inhibition of proliferation in response to 
A

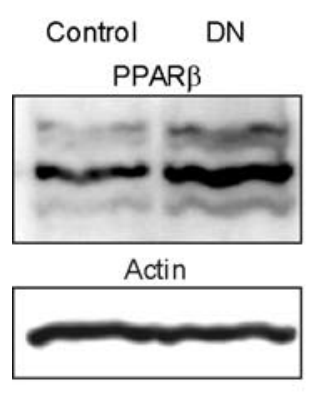

C

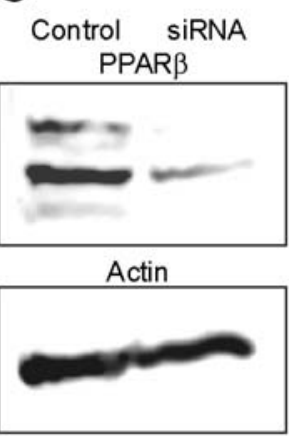

B

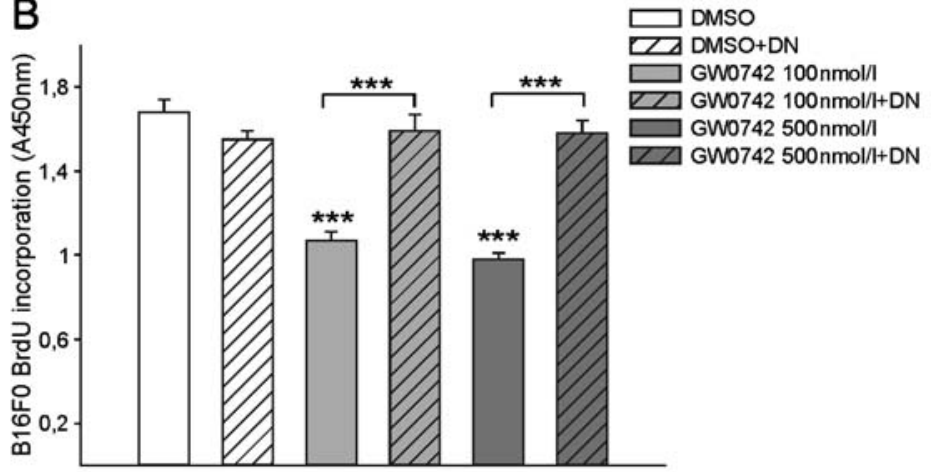

D

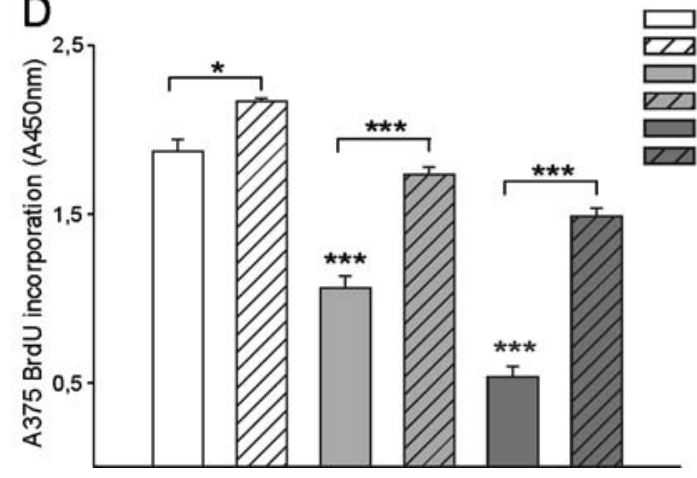

Fig. 3 Retroviral transduction of B16F0 melanoma cells with a dominant negative isoform of PPAR $\beta$ (PPAR $\beta D N$ ) and siRNA transfection of A375 melanoma cells against PPAR $\beta$ and subsequent treatment with a PPAR $\beta$ agonist GW0742. Western blot for PPAR $\beta$ from lysates of B16F0 cells without or with retroviral transduction of the PPAR $\beta D N$ (a). Note the increase in PPAR $\beta$ in the transduced cells reflecting the level of the transduced dominant negative PPAR $\beta$ expression. $\beta$-actin served as standard. Cells with or without retroviral transduction with the PPAR $\beta D N$, were treated with the PPAR $\beta$ agonist GW0742 for $24 \mathrm{~h}$. Note that the strong growth inhibitory effect of GW0742 was completely abolished in the cells expressing the dominant negative isoform of PPAR $\beta(n=4, P<0.001$; $\mathbf{b})$. Western blot from lysates of A375 cells transfected with siRNA constructs against human PPAR $\beta$ (c). Silenced and control cells were treated with the PPAR $\beta$ agonist GW0742 for $24 \mathrm{~h}$. Silencing of PPAR $\beta$ restores proliferation in the presence of different concentrations of the agonist $(n=8 ; \mathbf{d})$

function of one protein on the other factor. Also in A375 melanoma cells, a partial overlap of PPAR $\beta$ and WT1 could be detected (Fig. 7a). Addition of GW0742 significantly repressed the activity of the published WT1 promoter [42] in A375 melanoma cells (Fig. 7b). Transient co-transfection with a PPAR $\beta$ expression construct repressed the activity of the WT1 promoter reporter construct to a comparable extend (Fig. 7c). The combination of transient co-transfection with a PPAR $\beta$ expression construct and treatment with GW0742 had no additional effects on WT1 promoter activity, indicating a saturating effect of the individual approaches (data not shown). Using in silico analysis, a sequence region containing a predicted PPAR responsive element was identified in the WT1 promoter. This region shows a $62 \%$ homology from mouse to human and a $67 \%$ identity between mouse and zebrafish. In chromatin immunoprecipitation, we show that PPAR $\beta$ protein associates with this region, whereas no interaction could be detected in the 3'UTR of WT1. An antibody against acetylated histone $\mathrm{H} 3$ was used to check for nucleosome integrity (Fig. 7d). Electrophoretic mobility 
Fig. 4 Apoptosis assay of melanoma cells after pharmacological PPAR $\beta$ activation. TdT-dUTP terminal nick-end labelling (TUNEL) labelling of A375 melanoma cells was performed after $24 \mathrm{~h}$ of treatment with either GW0742 or GW501516. Nuclei were counterstained with DAPI (a). Cells in ten random fields were counted and the percentage of TUNEL-positive cells determined $(\mathbf{b}, \mathbf{c} ; n=4)$

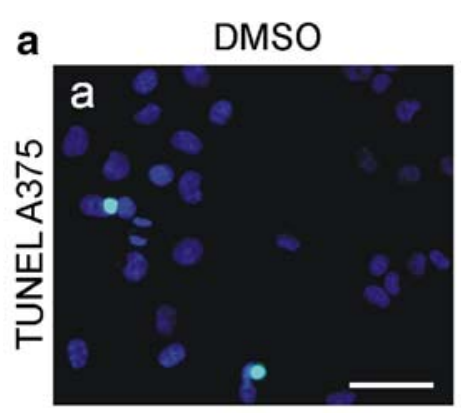

GW0742 100nmol/I

GW0742 500nmol/l
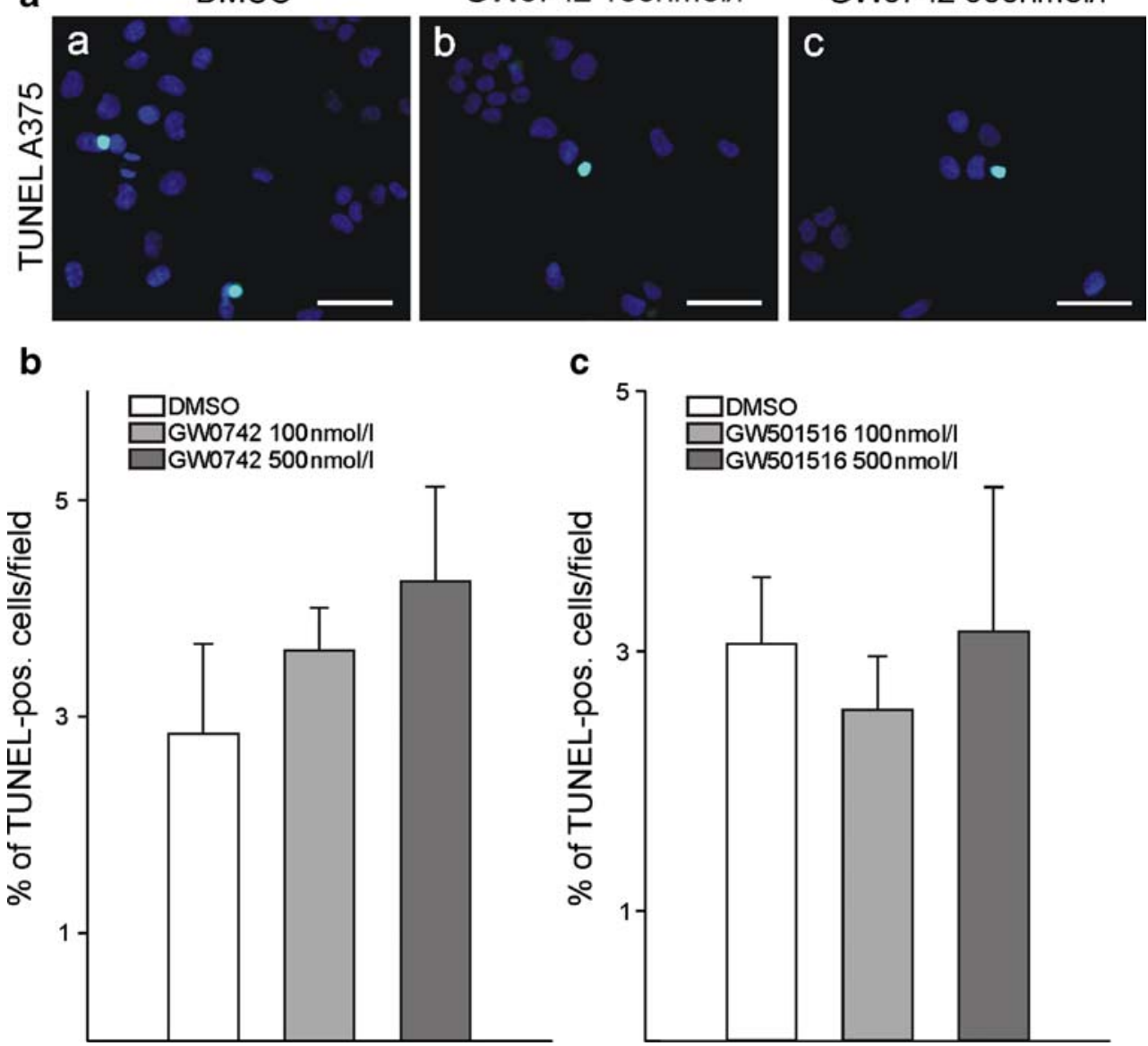

C

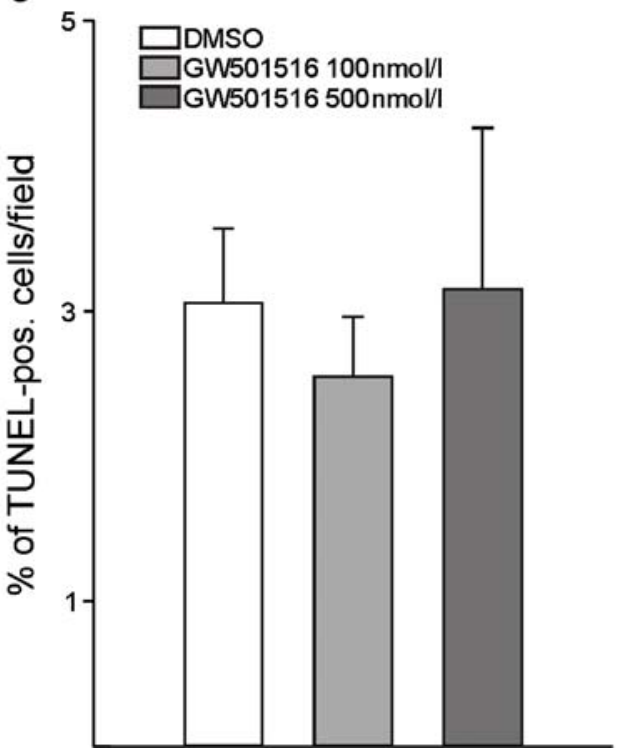

shift assays confirmed binding of PPAR $\beta$ to a $26 \mathrm{bp}$ oligonucleotide from the WT1 promoter (Fig. 7e). The published PPAR $\beta$ binding oligonucleotide from the acylCoA oxidase gene (Aco) [1] served as positive control. Incubation of the Aco/PPAR $\beta / R x R$ complex with a polyclonal PPAR $\beta$ antibody produced in rabbit supershifted the retardation band (lane 5 vs. 2). Under our reaction conditions, the binding affinity of the PPARbeta/RxR complex to the Aco oligonucleotide seems to be very high as a large excess of unlabelled competitor was needed to reduce the signal (lanes 3 and 4). Binding of the PPARbeta/ RxR complex to the oligonucleotide from the WT1 promoter seems to be of lower affinity, as it was easier to compete. In this case, incubation with the same antibody decreased the retardation band intensity (lane 10 vs. 7). Deletion of the identified binding site from the WT1 promoter construct completely abolished repression by cotransfection of the PPAR $\beta$ expression construct and by addition of GW0742 (Fig. 7f). In order to determine whether normal melanoma cell proliferation is indeed dependent of WT1 expression, transient transfection experiments with different WT1 splice variants were performed. Subsequently, the effects of GW0742 administration were investigated. In A375 melanoma cells over-expressing the
WT1(-KTS), (+KTS) or a combination of both isoforms, no decrease of WT1 expression on the protein level could be observed after pharmacological activation of PPAR $\beta$ (Fig. 7g). Over-expression of WT1(-KTS) stimulated nestin expression whereas WT1(+KTS) increased zyxin protein levels. Combination of both isoforms resulted in higher nestin and zyxin protein levels. Consistently, WT1 over-expression restored the proliferative potential of the melanoma cells also in the presence of the PPAR $\beta$ activator GW0742 (Fig. 7h).

\section{Discussion}

Recently, PPAR $\beta$ activation became in focus as an interesting novel approach for the treatment of diabetes, metabolic syndrome, associated cardiovascular diseases and a potential tumour therapy [5, 25, 26, 39, 43]. Interestingly, an association between increased risk of melanoma and high body mass index has been described [34] whereas exercise appeared to have a protective effect against melanoma development [37]. Whether PPAR $\beta$ is involved in these associations is presently unclear, but several studies have shown that PPAR $\beta$ activation mimics 


\section{a}

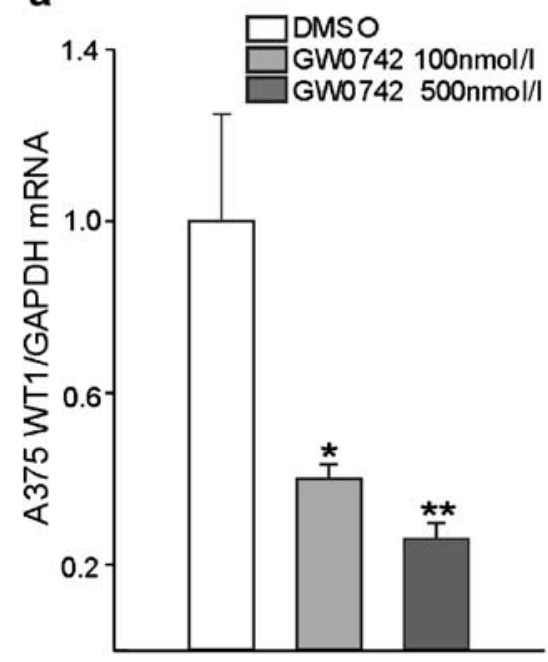

c
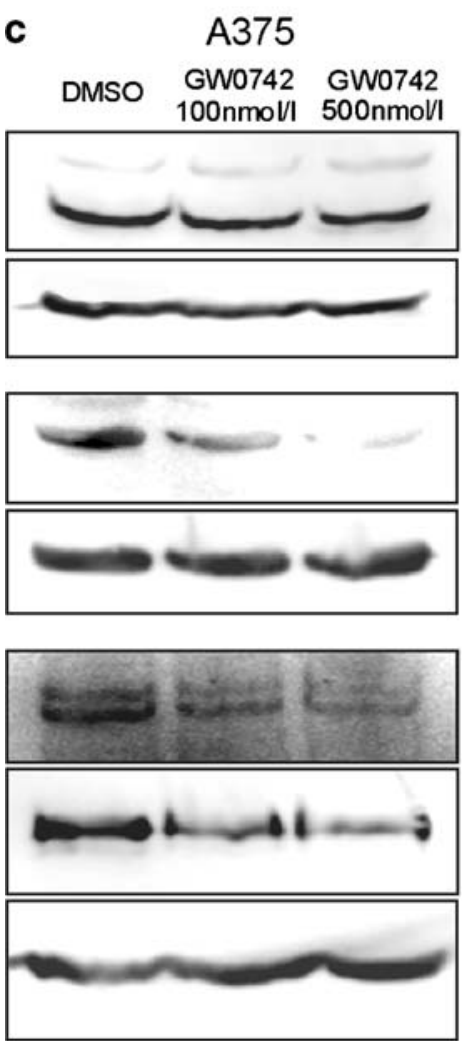

Fig. 5 Pharmacological PPAR $\beta$ activation decreases WT1 expression levels in melanoma cells. Quantitative reverse transcription (RT)-PCR for WT1 in A375 (a) and B16F0 (b) melanoma cells treated with GW0742 for $24 \mathrm{~h}$. WT1 expression was normalised to GAPDH $(n=8, P<0.01$, $P<0.05$ ). Western blot for PPAR $\beta, \mathrm{WT} 1$, nestin and zyxin from lysates

exercise effects in heart, skeletal muscle and adipose tissue $[3,30,43]$. Our present data using immunohistochemistry on human melanoma samples clearly show that PPAR $\beta$ is expressed in these tumours. In normal skin, PPAR $\beta$ expression in vivo had been described already earlier in keratinocytes, hair follicles, sebaceous and b

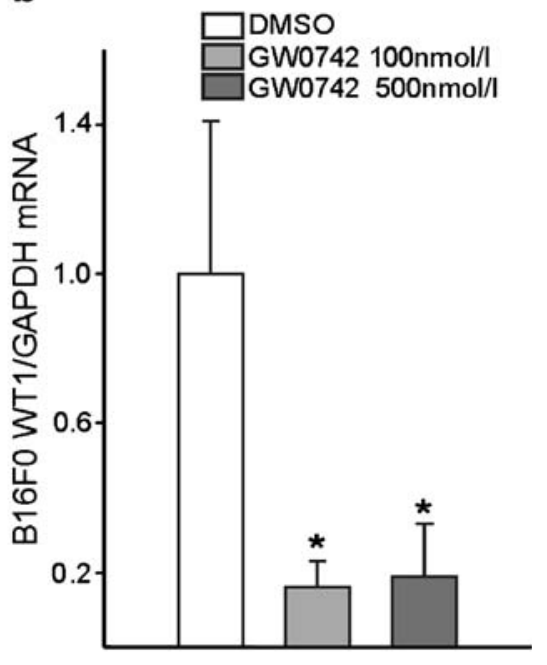

d

B16F0

GW0742 GW0742 $100 \mathrm{nmol} / \mathrm{l} 500 \mathrm{nmol} / \mathrm{l}$

PPAR $\beta$

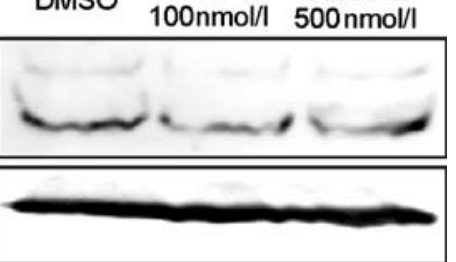

WT1

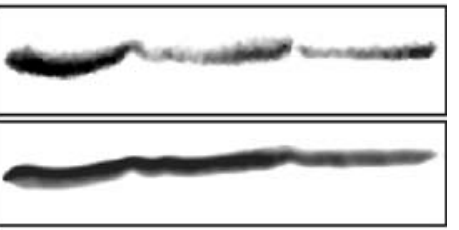

Nestin

Zyxin
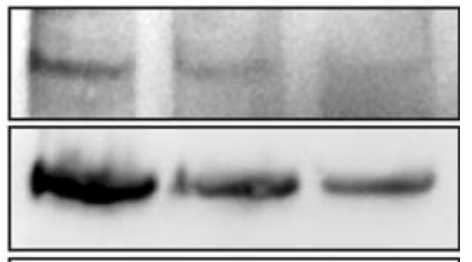

Actin

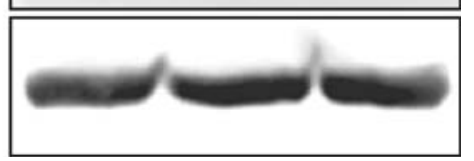

of A375 (c) and B16F0 (d) melanoma cells treated with GW0742. Note that PPAR $\beta$ expression remained stable upon pharmacological PPAR $\beta$ activation, whereas WT1, nestin and zyxin expression was decreased. GAPDH and $\beta$-actin served as standards ( $n=8$ each)

eccrine glands (reviewed in [28]), which is in agreement with our findings. PPAR $\beta$ expression in melanocytes had been shown by PCR from cultured melanocytes in vitro [21]; however, the expression and function of PPAR $\beta$ in melanocytes and melanoma remained elusive. We show here that PPAR $\beta$ is expressed in melanocytes and 
Fig. 6 PPAR $\beta$ and WT1 colocalise partially in melanoma. In normal skin $(\mathbf{a}, \mathbf{b})$, no signal for WT1 could be observed in immunofluorescence doublelabelling. Partial co-localisation (yellow) of PPAR $\beta$ (Cy2, green) and WT1 (Cy3, red) could be detected in melanoma (c-f). Nuclei were counterstained with DAPI (blue). Scale bars indicate $50 \mu \mathrm{m}$
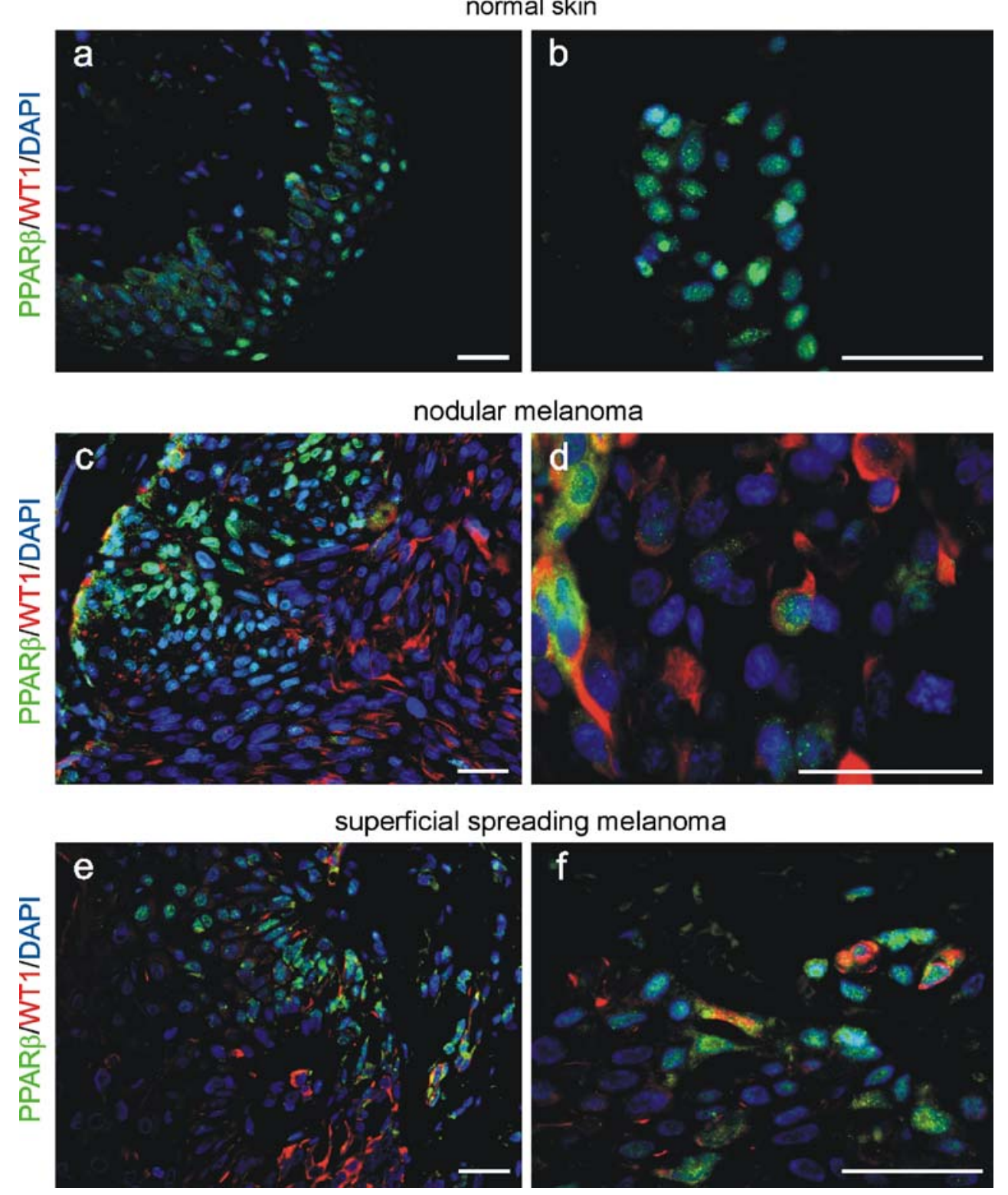

melanoma cells in vivo. In melanomas, the expression pattern was heterogeneous. Especially in superficial spreading melanomas, PPAR $\beta$ was confined to the tumorigenic vertical growth phase component of the tumour. Moreover, in all melanomas analysed, we observed a nuclear and cytoplasmic granular staining, in contrast to the normal skin where the expression was nuclear. At present, it is unclear what functional significance this cytoplasmic localisation might have. Interestingly, a similar phenomenon has been described for the WT1 transcription factor. Shuttling of WT1 between the nucleus and the cytoplasm has been reported recently [32]. WT1 protein in the cytoplasm interacts with splicing factors thereby promoting post-transcriptional modifications [6]. Especially in tumours, WT1 localises predominantly to the cytoplasm [19]. Although PPAR $\beta$ in melanoma is localised also to some extent in the cytoplasm, a potential role as a splicing factor/co-activator remains to be determined.

To investigate the functional role of PPAR $\beta$ in melanoma, we used different melanoma cell lines of human and mouse origin and treated the cells independently with two different highly specific PPAR $\beta$ agonists. In agreement with reported results for a breast cancer and another melanoma cell line [15], we observed an inhibition of proliferation. This was confirmed independently by labelling for PCNA and measurements of BrdU incorporation by ELISA. Surprisingly, in contrast to the study mentioned above, we observed this effect already significantly earlier and at a 100 -fold lower dose of the specific PPAR $\beta$ agonist. Whether theses discrepancies are due to different cell culture conditions or variations in the expression levels of 


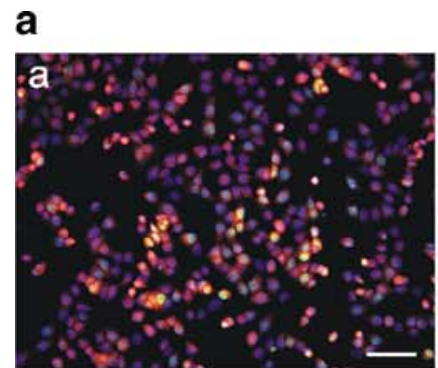

A375 WT1/PPARß/DAPI
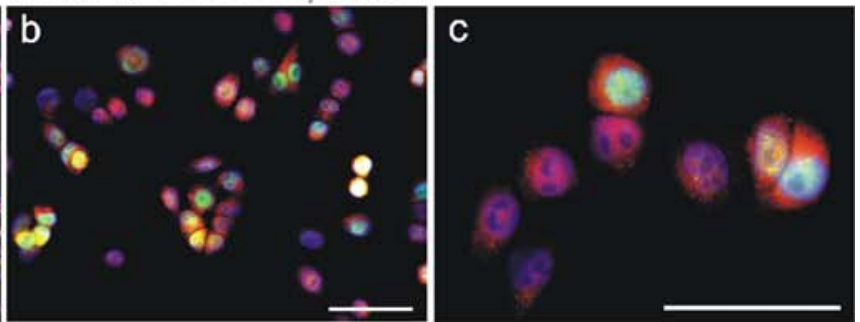

b

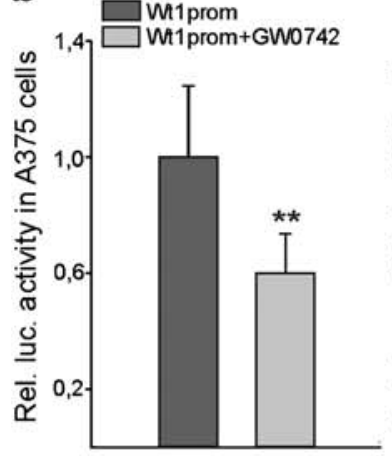

e

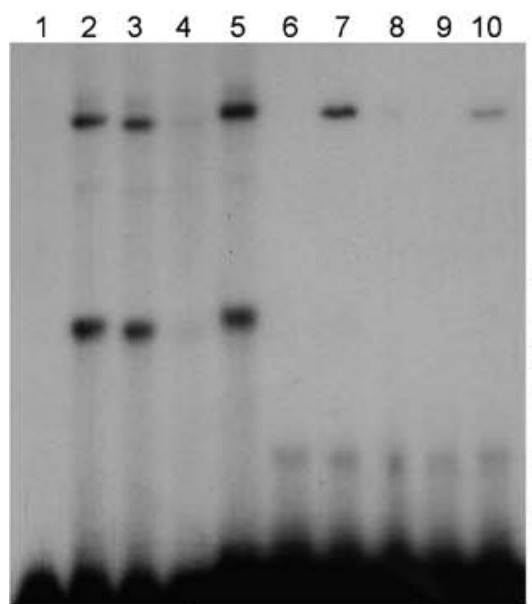

g

WT1
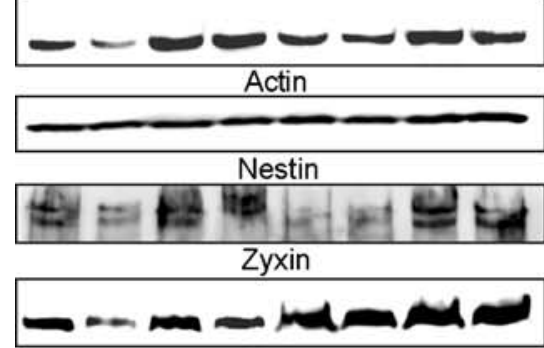

Actin

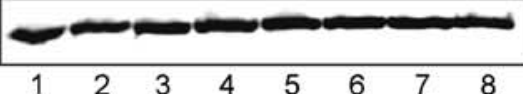

\section{1: DMSO}

2: GW0742 100nmol/

3: +(-KTS) + DMSO

4: +(-KTS) + GWO742 100 nmol/

$5:+(+$ KTS $)+$ DMSO

$6 \mathrm{:}+(+\mathrm{KTS})+$ GW0742 100 $\mathrm{nmol} / \mathrm{l}$

7: + (-KTS/+KTS $)+$ DMSO

8: +(-KTS/+KTS) + GW0742 100 $\mathrm{nmol} / 1$
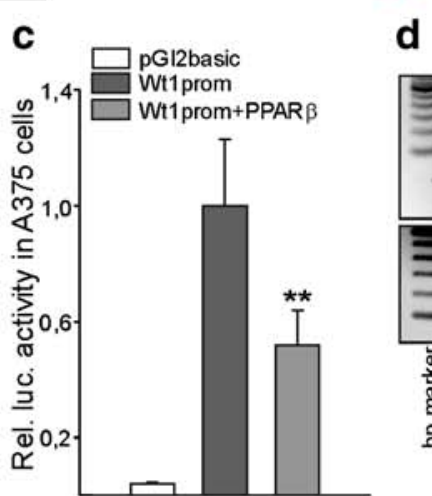

d
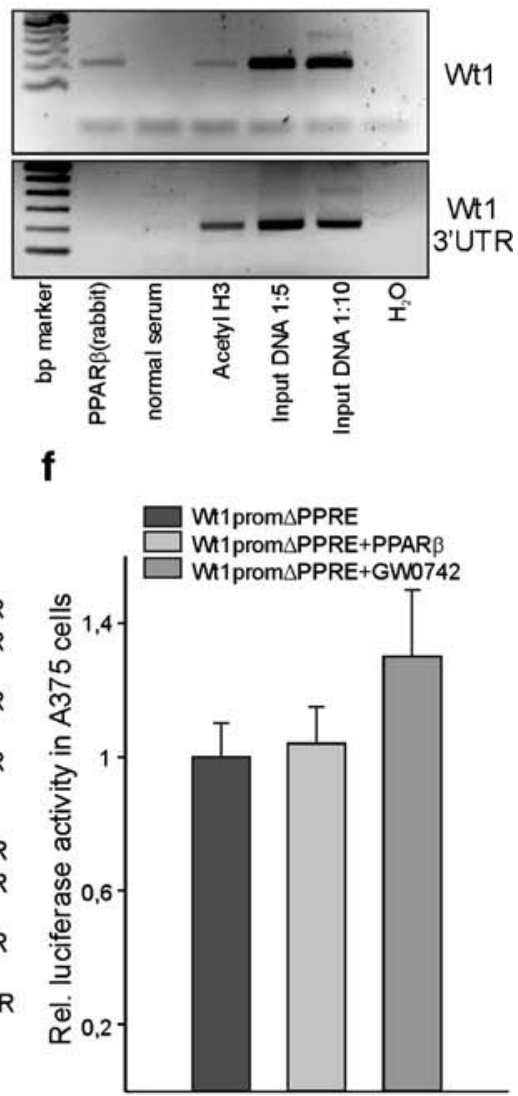

h

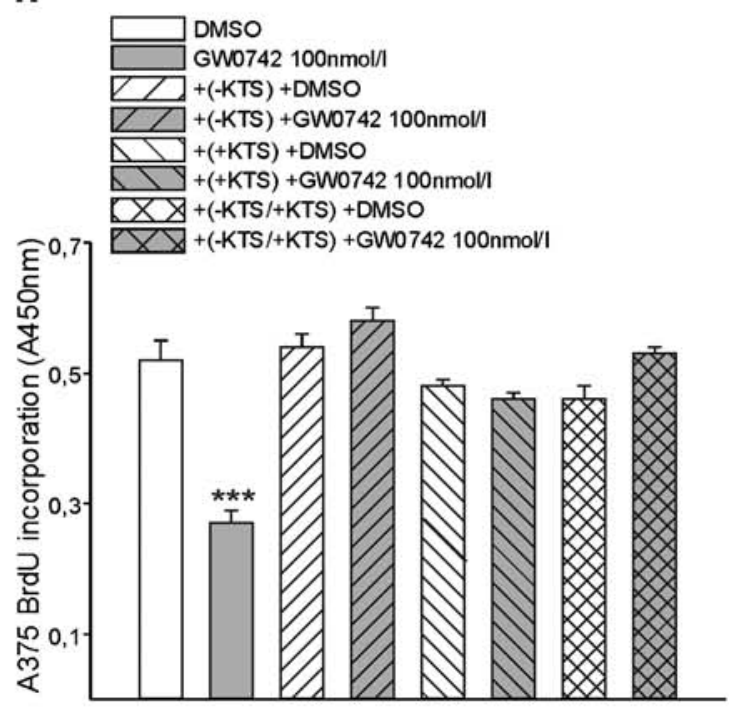

1: Aco

2: $A C O+P P A R \beta+R \times R$

3: $A c 0+P P A R \beta+R \times R$

$+10 x$ competitor

4: Aco+PPARB+RxR

$+50 x$ competitor

5: Aco+PPAR $\beta+R \times R$

$+A b$ (rabbit)

6: $W$ t1

7: $W 11+P P A R \beta+R \times R$

8: $W 11+P P A R \beta+R \times R$

$+10 x c o m p e t i t o r$

9: $W 11+P P A R \beta+R \times R$

$+50 x$ competitor

10: $W t 1+P P A R \beta+R \times R$ $+A b$ (rabbit) 
Fig. 7 PPAR $\beta$ represses WT1. Co-localisation of PPAR $\beta$ (Cy2, green) and WT1 $(\mathrm{Cy} 3$, red $)$ in A375 melanoma cells (a). Nuclei were counterstained with DAPI (blue). Scale bars indicate $50 \mu \mathrm{m}$. b Transient transfection of the WT1 promoter in a luciferase vector in the presence of vehicle or $200 \mathrm{nM}$ GW0742 in A375 cells. Luciferase activities were normalised for the activity of co-transfected $\beta$ galactosidase $(n=8, P<0.01)$. c Transient co-transfections of a WT1 promoter construct together with a PPAR $\beta$ expression construct in A375 melanoma cells $(n=12, P<0.01)$. d Chromatin immunoprecipitation to analyse PPAR $\beta$ protein interaction with WT1 regulatory elements. PPAR $\beta$ protein binds to the WT1 promoter (upper panel), but not to the 3'-untranslated region (UTR) of WT1 (lower panel). Input DNA and immunoprecipitates obtained with acetylated histone 3 antibody served as positive controls. Negative controls were performed with normal serum instead of specific antibodies and with DNase-free water for the PCR. e Electrophoretic mobility shift assay demonstrating binding of the PPAR $\beta / \mathrm{RXR} \alpha$ complex to the predicted consensus element of the WT1 promoter (lane 7). Unlabelled oligonucleotide from the acyl-CoA oxidase gene in the indicated molar excess was used as competitor (lanes 3, 4, 8 and 9). Supershift assays were performed by incubating the binding reactions with a polyclonal anti-PPAR $\beta$ antibody (Ab rabbit, lanes 5 and 10). An oligonucleotide from the acyl-CoA oxidase gene served as positive control [1]. f Transient co-transfections of a WT1 construct with deletion of the identified 26 bp consensus motif together with PPAR $\beta$ expression constructs or in the presence of $200 \mathrm{nM}$ GW0742 in A375 melanoma cells $(n=12)$. Note that the $26 \mathrm{bp}$ deletion abolished transactivation of the WT1 promoter by PPAR $\beta$ or GW0742. $\mathbf{g}$ Western blot for WT1, nestin and zyxin from lysates of A375 cells transiently transfected with the WT1 $(-\mathrm{KTS})$ or $(+\mathrm{KTS})$ variant or a combination of both isoforms in a $50: 50 \%$ ratio. Cells were subsequently treated with vehicle or $100 \mathrm{nM} \mathrm{GW0742.} \mathrm{Note} \mathrm{that} \mathrm{the}$ decrease of WT1 expression by pharmacological PPAR $\beta$ activation is abolished in the WT1 over-expressing cells. $\beta$-actin served as standard. h BrdU incorporation assay of the WT1 over-expressing cells, without or with pharmacological PPAR $\beta$ activation. The growth inhibitory effect of GW0742 is abolished in the cells over-expressing any of the WT1 splice variants $(n=4, P<0.001)$

PPAR $\beta$ in the cell lines used remains uncertain. Although we observed certain variability in the growth inhibitory effect of PPAR $\beta$ activation, the inhibition of proliferation was reproducible using two different PPAR $\beta$ agonists in both cell lines tested. To test whether the observed inhibition of proliferation was specifically mediated via PPAR $\beta$ receptors, we repeated the pharmacological PPAR $\beta$ stimulation with GW0742 in B16F0 cells retrovirally transduced with a dominant negative isoform of PPAR $\beta$ and in A375 cells transfected with a siRNA against PPAR $\beta$. Of note, the retrovirally transduced or silenced cells did not respond to the growth inhibitory effect of GW0742. Thus, proliferation of melanoma cells seems to be inhibited specifically by PPAR $\beta$ activation.

Several other molecules have been implicated in melanoma cell proliferation, e.g. nestin [12, 23] and zyxin [41] correlate positively with melanoma proliferation. Recently, we showed that the Wilms' tumour suppressor WT1 is important for melanoma cell proliferation via activation of nestin and zyxin [45]. WT1 is a transcription factor originally identified as a tumour suppressor based on mutational inactivation in nephroblastoma [18]. However, expression of WT1 in different adult tumours and tumour-derived cell lines has been described, suggesting that WT1 might also be able to act as an oncogene (for review, see [19]).

Interestingly, here we show that pharmacological PPAR $\beta$ activation decreases WT1 expression on the RNA and protein levels. As reported recently using a siRNA approach, inhibition of WT1 results in reduced melanoma cell proliferation without affecting apoptosis [45], which was confirmed in the present study. To test for a possible direct regulation of WT1 by PPAR $\beta$, we performed doublelabelling experiments. The only partial overlapping expression pattern of PPAR $\beta$ and WT1 in melanoma in vivo and in melanoma cells in vitro and our observed downregulation of WT1 in response to PPAR $\beta$ activation suggested that PPAR $\beta$ might act as a repressor of WT1. Several lines of evidence confirmed that WT1 represents a relevant target of PPAR $\beta$ in melanoma cells. First, transient transfection experiments showed that the activity of the WT1 promoter was significantly inhibited by pharmacological PPAR $\beta$ activation. Second, PPAR $\beta$ co-transfection also inhibited the activity of the WT1 promoter indicating a specific effect of PPAR $\beta$ on the WT1 promoter. Third, in chromatin immunoprecipitation experiments we confirmed direct binding of PPAR $\beta$ to the WT1 promoter sequence, but not to the $3^{\prime}$-UTR of WT1. Fourth, in electrophoretic mobility shift assays, we identified a 26 bp element in the WT1 promoter, which directly binds to the $\operatorname{PPAR} \beta / \mathrm{R} \times R \alpha$ protein complex. Finally, mutation of the identified binding site abolished repression by PPAR $\beta$ or the agonist GW0742.

Interestingly, over-expression of WT1 in melanoma cells restored the proliferative potential of these tumour cells overcoming the growth inhibitory effects of PPAR $\beta$ activation. This confirms our recent finding that WT1 is required for melanoma cell proliferation [45].

To test whether PPAR $\beta$ activation affected not only WT1, but also WT1 downstream target genes, we analysed protein levels of zyxin and nestin [45], which are both involved in melanoma cell proliferation. The dosedependent reduction of nestin and zyxin upon pharmacological PPAR $\beta$ activation suggests that not only WT1, but also its downstream signalling in melanoma cells is consistently affected by PPAR $\beta$ stimulation. Transient over-expression of WT1(-KTS) resulted in upregulation of nestin, which is consistent with a previous report [46], whereas over-expression of WT1(+KTS) stimulated zyxin expression. Whether zyxin represents a direct target of WT1(+KTS) remains to be determined in future studies. As nestin [12, 23] and zyxin [41] are both involved in melanoma cell proliferation, it is not surprising that overexpression of either WT1(-KTS) or WT1(+KTS) restored melanoma cell proliferation. In these WT1 over-expression 
experiments, pharmacological PPAR $\beta$ activation did not have an effect on melanoma cell proliferation, since the different WT1 expression constructs are under control of a CMV promoter, but did not include the WT1 promoter sequence.

Although some molecules regulating WT1 have been reported, e.g. Pax2/8 [7, 13], Pea3 [10], NF-kB [8] or Hif- $1 \alpha$ [42], the repression of WT1 by PPAR $\beta$ and subsequent inhibition of melanoma cell proliferation is of special interest, as specific pharmacological activators of PPAR $\beta$ already exist. Whether pharmacological PPAR $\beta$ activation in vivo is sufficient to inhibit melanoma growth will be clarified in further studies. Nevertheless, it is likely that PPAR $\beta$ activation might inhibit melanoma growth as it has been shown that colon carcinoma cells express PPAR $\beta$; and colon carcinogenesis could be inhibited by the PPAR $\beta$ agonist GW0742 [26].

In summary, we have shown here that PPAR $\beta$ is expressed in melanocytes and melanoma in vivo. PPAR $\beta$ activation inhibits melanoma cell proliferation, which involves transcriptional repression of WT1.

Acknowledgements The human A375 cell line was provided by F. Tarantini (University of Florence, Italy), the mouse B16F0 cell line by R. Ballotti (INSERM U895, Faculty of Medicine, Nice). GW0742 was a gift from T.M. Willson (GlaxoSmithKline). We thank G. Manfroni, G. Visciano and B. Szczepaniak for technical assistance. The authors thank K. D. Wagner for critical reading of the manuscript and helpful comments. N. Wagner was the recipient of a fellowship from the Fondation de France. The study was financially supported by the Fondation Cœur et Artères and the Association pour la Recherche sur le Cancer.

Conflict of interest The authors declare no conflict of interest.

Open Access This article is distributed under the terms of the Creative Commons Attribution Noncommercial License which permits any noncommercial use, distribution, and reproduction in any medium, provided the original author(s) and source are credited.

\section{References}

1. Amri EZ, Bonino F, Ailhaud G, Abumrad NA, Grimaldi PA (1995) Cloning of a protein that mediates transcriptional effects of fatty acids in preadipocytes. Homology to peroxisome proliferator-activated receptors. J Biol Chem 270:2367-2371

2. Balch CM, Buzaid AC, Soong SJ et al (2001) Final version of the American Joint Committee on Cancer staging system for cutaneous melanoma. J Clin Oncol 19:3635-3648

3. Bastie C, Luquet S, Holst D, Jehl-Pietri C, Grimaldi PA (2000) Alterations of peroxisome proliferator-activated receptor delta activity affect fatty acid-controlled adipose differentiation. J Biol Chem 275:38768-38773

4. Berwick M, Wiggins C (2006) The current epidemiology of cutaneous malignant melanoma. Front Biosci 11:1244-1254
5. Burkart EM, Sambandam N, Han X et al (2007) Nuclear receptors PPARbeta/delta and PPARalpha direct distinct metabolic regulatory programs in the mouse heart. J Clin Invest 117:3930-3939

6. Davies RC, Calvio C, Bratt E, Larsson SH, Lamond AI, Hastie ND (1998) WT1 interacts with the splicing factor U2AF65 in an isoform-dependent manner and can be incorporated into spliceosomes. Genes Dev 12:3217-3225

7. Dehbi M, Gharemani M, Lechner M, Dressler G, Pelletier J (1996) The paired-box transcription factor, PAX2, positively modulates expression of the Wilms' tumor suppressor gene (WT1). Oncogene 13:447-453

8. Dehbi M, Hiscott J, Pelletier J (1998) Activation of the wt1 Wilms' tumor suppressor gene by NF-kB. Oncogene 16:20332039

9. de Vries E, Coebergh JW (2004) Cutaneous malignant melanoma in Europe. Eur J Cancer 40:2355-2366

10. Discenza MT, Vaz D, Hassell JA, Pelletier J (2004) Activation of the WT1 tumor suppressor gene promoter by Pea3. FEBS Lett 560:183-191

11. Eastham LL, Mills CN, Niles RM (2008) PPARalpha/gamma expression and activity in mouse and human melanocytes and melanoma cells. Pharm Res 25:1327-1333

12. Flørenes VA, Holm R, Myklebost O, Lendahl U, Fodstad O (1994) Expression of the neuroectodermal intermediate filament nestin in human melanomas. Cancer Res 54:354-356

13. Fraizer GC, Shimamura R, Zhang X, Saunders FG (1997) PAX 8 Regulates Human WT1 Transcription through a Novel DNA Binding Site. J Biol Chem 272:30678-30687

14. Garbe C, Eigentler TK (2007) Diagnosis and treatment of cutaneous melanoma: state of the art 2006. Melanoma Res $17: 117-127$

15. Girroir EE, Hollingshead HE, Billin AN et al (2008) Peroxisome proliferator-activated receptor-beta/delta (PPARbeta/delta) ligands inhibit growth of UACC903 and MCF7 human cancer cell lines. Toxicology 243:236-243

16. Grabacka M, Placha W, Plonka PM et al (2004) Inhibition of melanoma metastases by fenofibrate. Arch Dermatol Res 296:5458

17. Grabacka M, Plonka PM, Urbanska K, Reiss K (2006) Peroxisome proliferator-activated receptor alpha activation decreases metastatic potential of melanoma cells in vitro via downregulation of Akt. Clin Cancer Res 12:3028-3036

18. Haber DA, Buckler AJ, Glaser T et al (1990) An internal deletion within an $11 \mathrm{p} 13$ zinc finger gene contributes to the development of Wilms' tumour. Cell 61:1257-1269

19. Hohenstein P, Hastie ND (2006) The many facets of the Wilms' tumour gene, WT1. Hum Mol Genet 15:R196-R201

20. Huin C, Corriveau L, Bianchi A, Keller JM, Collet P, KrémarikBouillaud P et al (2000) Differential expression of peroxisome proliferator-activated receptors (PPARs) in the developing human fetal digestive tract. J Histochem Cytochem 48:603-611

21. Kang HY, Chung E, Lee M, Cho Y, Kang WH (2004) Expression and function of peroxisome proliferator-activated receptors in human melanocytes. Br J Dermatol 150:462-468

22. Kim DJ, Murray IA, Burns AM, Gonzalez FJ, Perdew GH, Peters JM (2005) Peroxisome proliferator-activated receptor-beta/delta inhibits epidermal cell proliferation by down-regulation of kinase activity. J Biol Chem 280:9519-9527

23. Klein WM, Wu BP, Zhao S, Wu H, Klein-Szanto AJ, Tahan SR (2007) Increased expression of stem cell markers in malignant melanoma. Mod Pathol 20:102-107

24. Kliewer SA, Umesono K, Noonan DJ, Heyman RA, Evans RM (1992) Convergence of 9-cis retinoic acid and peroxisome proliferator signalling pathways through heterodimer formation of their receptors. Nature 358:771-774 
25. Luquet S, Lopez-Soriano J, Holst D, Fredenrich A, Melki J, Rassoulzadegan M et al (2003) Peroxisome proliferator-activated receptor delta controls muscle development and oxidative capability. FASEB J 17:2299-2301

26. Marin HE, Peraza MA, Billin AN et al (2006) Ligand activation of peroxisome proliferator-activated receptor beta inhibits colon carcinogenesis. Cancer Res 66:4394-4401

27. Michalik L, Desvergne B, Tan NS et al (2001) Impaired skin wound healing in peroxisome proliferator-activated receptor (PPAR)alpha and PPARbeta mutant mice. J Cell Biol 154:799-814

28. Michalik L, Wahli W (2007) Peroxisome proliferator-activated receptors (PPARs) in skin health, repair and disease. Biochim Biophys Acta 1771:991-998

29. Mössner R, Schulz U, Krüger U et al (2002) Agonists of peroxisome proliferator-activated receptor gamma inhibit cell growth in malignant melanoma. J Invest Dermatol 119:576-582

30. Narkar VA, Downes M, Yu RT, Embler E, Wang YX, Banayo E (2008) AMPK and PPARdelta agonists are exercise mimetics. Cell 134:405-415

31. Nicol CJ, Yoon M, Ward JM et al (2004) PPARgamma influences susceptibility to DMBA-induced mammary, ovarian and skin carcinogenesis. Carcinogenesis 25:1747-1755

32. Niksic M, Slight J, Sanford JR, Caceres JF, Hastie ND (2004) The Wilms' tumour protein (WT1) shuttles between nucleus and cytoplasm and is present in functional polysomes. Hum Mol Genet 13(4):463-471

33. Norton AJ, Jordan S, Yeomans P (1994) Brief, high-temperature heat denaturation (pressure cooking): a simple and effective method of antigen retrieval for routinely processed tissues. J Pathol 4:371-379

34. Odenbro A, Gillgren P, Bellocco R, Boffetta P, Håkansson N, Adami J (2007) The risk for cutaneous malignant melanoma, melanoma in situ and intraocular malignant melanoma in relation to tobacco use and body mass index. Br J Dermatol 156:99-105

35. Rees JL (2008) Melanoma: what are the gaps in our knowledge. PLoS Med 5:e122

36. Sher T, Yi HF, McBride OW, Gonzalez FJ (1993) cDNA cloning, chromosomal mapping, and functional characterization of the human peroxisome proliferator activated receptor. Biochemistry 32:5598-5604
37. Shors AR, Solomon C, McTiernan A, White E (2001) Melanoma risk in relation to height, weight, and exercise (United States). Cancer Causes Control 12:599-606

38. Tan NS, Michalik L, Noy N et al (2001) Critical roles of PPAR beta/delta in keratinocyte response to inflammation. Genes Dev 15:3263-3277

39. Tanaka T, Yamamoto J, Iwasaki S et al (2003) Activation of peroxisome proliferator-activated receptor delta induces fatty acid beta-oxidation in skeletal muscle and attenuates metabolic syndrome. Proc Natl Acad Sci U S A 100:15924-15929

40. Thuillier P, Anchiraico GJ, Nickel KP et al (2000) Activators of peroxisome proliferator-activated receptor-alpha partially inhibit mouse skin tumor promotion. Mol Carcinog 29:134-142

41. van der Gaag EJ, Leccia MT, Dekker SK, Jalbert NL, Amodeo DM, Byers HR (2002) Role of zyxin in differential cell spreading and proliferation of melanoma cells and melanocytes. J Invest Dermatol 118:246-254

42. Wagner KD, Wagner N, Wellmann S et al (2003) Oxygenregulated expression of the Wilms' tumor suppressor Wt1 involves hypoxia-inducible factor-1 (HIF-1). FASEB J 17:1364-1366

43. Wagner N, Jehl-Piétri C, Lopez P et al (2009) Peroxisome proliferator-activated receptor beta stimulation induces rapid cardiac growth and angiogenesis via direct activation of calcineurin. Cardiovasc Res 83:61-71

44. Wagner N, Michiels JF, Schedl A, Wagner KD (2008) The Wilms' tumour suppressor WT1 is involved in endothelial cell proliferation and migration: expression in tumour vessels in vivo. Oncogene 26:3662-3672

45. Wagner N, Panelos J, Massi D, Wagner KD (2008) The Wilms' tumor suppressor WT1 is associated with melanoma proliferation. Pflugers Arch 455:839-847

46. Wagner N, Wagner KD, Scholz H, Kirschner KM, Schedl A (2006) Intermediate filament protein nestin is expressed in developing kidney and heart and might be regulated by the Wilms' tumor suppressor Wt1. Am J Physiol Regul Integr Comp Physiol 291:R779-R787

47. Wagner N, Wagner KD, Theres H, Englert C, Schedl A, Scholz H (2005) Coronary vessel development requires activation of the TrkB neurotrophin receptor by the Wilms' tumor transcription factor Wt1. Genes Dev 21:2631-2642 